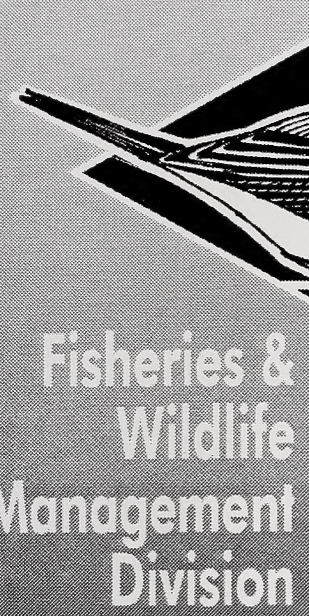

ИESOUEOE STIIIS WIO

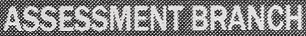

\title{
Burrowing Owl Trend Block Survey and Monitoring, Brooks and Hanna Areas
}
D. Scobie and
R. Russell

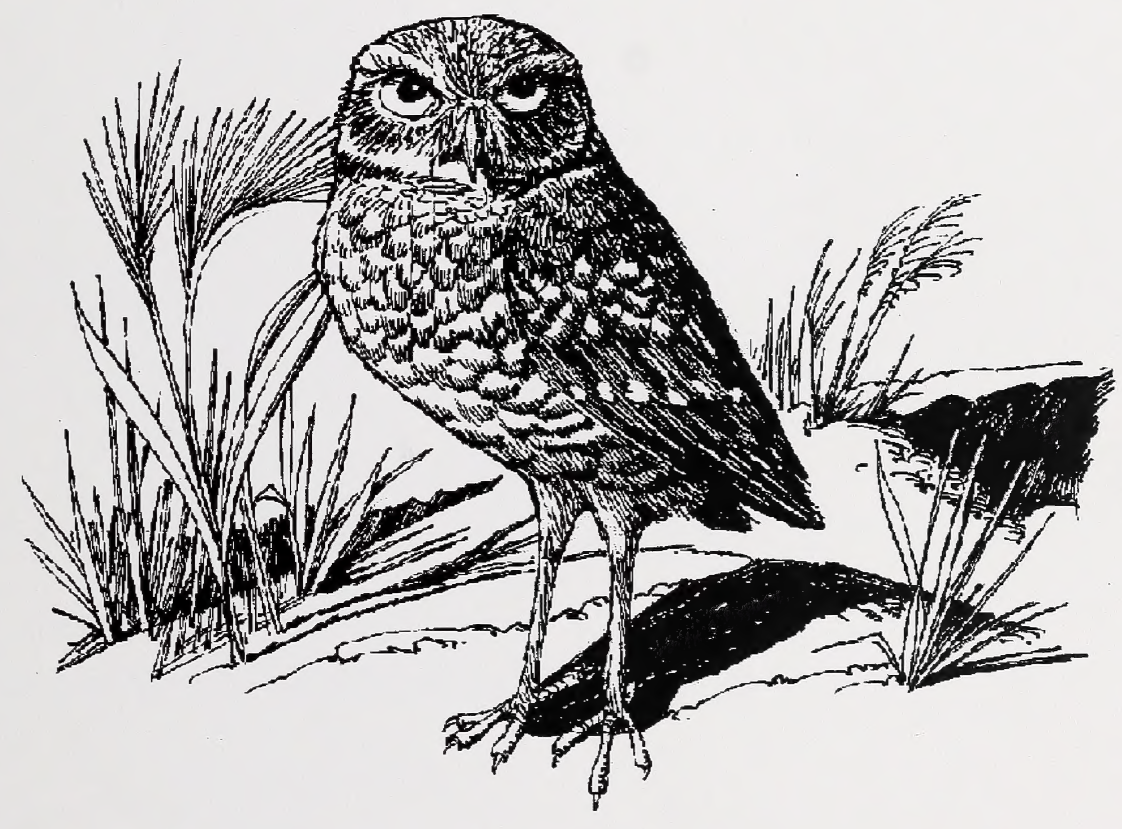

Alberta Species at Risk Report No. 8 
Digitized by the Internet Archive in 2016 


\title{
Burrowing Owl Trend Block Survey and Monitoring, Brooks and Hanna Areas
}

\author{
D. Scobie \\ and \\ R. Russell
}

Alberta Species at Risk Report No. 8

October 2000 
Publication No.: I/009

ISBN: 0-7785-1761-6 (Printed Edition)

ISBN: 0-7785-1762-4 (On-line Edition)

ISSN: 1496-7219 (Printed Edition)

ISSN: 1496-7146 (On-line Edition)

Illustration: Brian Huffman

For copies of this report, contact:

Information Centre - Publications

Alberta Environment

Main Floor, Great West Life Building

9920 - 108 Street

Edmonton, Alberta

Canada

T5K 2M4

Telephone: (780) 422-2079

\section{OR}

Information Service

Alberta Environment

\#100, 3115 - 12 Street NE

Calgary, Alberta

Canada

T2E 7J2

Telephone: (403) 297-3362

This publication may be cited as:

Scobie, D., and Russell, R. 2000. Burrowing Owl Trend Block Survey and Monitoring, Brooks and Hanna Areas. Alberta Sustainable Resource Development, Fisheries and Wildlife Management Division, Alberta Species at Risk Report No. 8, Edmonton, AB. 11 pp. 


\section{TABLE OF CONTENTS}

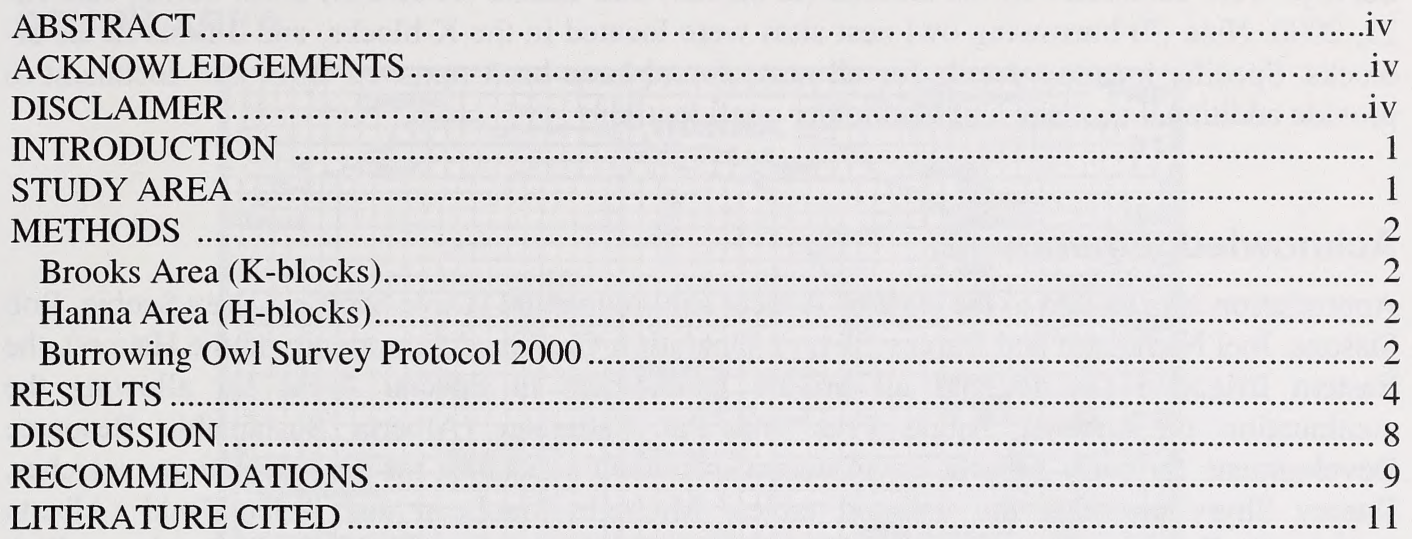

\section{LIST OF FIGURES}

Figure 1. Location of trend blocks in Brooks and Hanna............................................................. 1

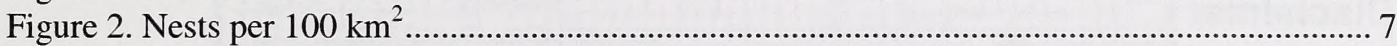

Figure 3. Brooks K-block trend (linear regression).................................................................... 7

Figure 4. Hanna H-block trend (linear regression). ........................................................................ 7

Figure 5. Average number of juvenile owls observed per successful nest site................................. 8

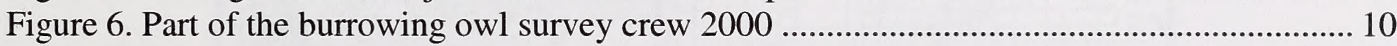

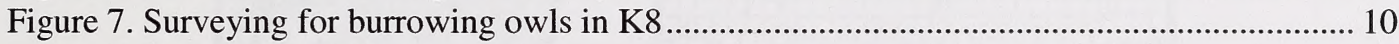

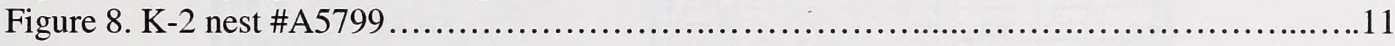

\section{LIST OF TABLES}

Table 1. Results of K-block burrowing owl 2000 survey................................................................. 4

Table 2. Results of H-block burrowing owl 2000 survey................................................................ 5

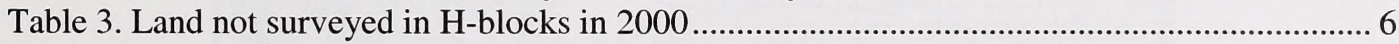

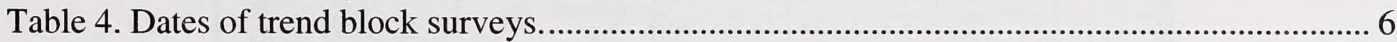

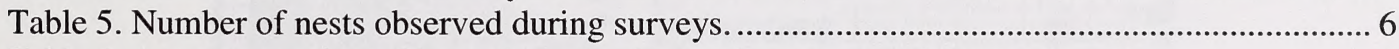

Table 6. Average number of juvenile owls observed per successful nest site................................ 8 


\section{Abstract}

Surveys were conducted in the Brooks (K-blocks) and Hanna (H-blocks) areas during June1221,2000 . Nine (9) burrowing owl nest sites were located in the K-blocks, and 2 nests in the Hblocks. Specific location details for all nests found have been removed from this document to provide additional nest site and landholder confidentiality.

\section{Acknowledgements}

Appreciation is extended to the staff of Avocet Environmental (Dave Scobie, Corey Scobie, Rob Sissons, Joel Nicholson and Darcey Shyry), Operation Grassland Community (Julie Hauser), the Eastern Irrigation District and all private landholders in Special Areas for allowing the continuation of surveys. Angie Fraz and Pat Patterson (Alberta Sustainable Resource Development, formerly Alberta Environment) provided assistance for the productivity searches. Darcey Shyry provided the updated tables. Michelle MacLean and Arlen Todd (Alberta Sustainable Resource Development) provided editorial assistance. The Alberta Species at Risk Program (Alberta Sustainable Resource Development) provided funding.

\section{Disclaimer}

The opinions and recommendations expressed are those of the authors, and not necessarily those of Alberta Sustainable Resource Development. 
INTRODUCTION (please refer to Shyry 1999.)

\section{STUDY AREA}

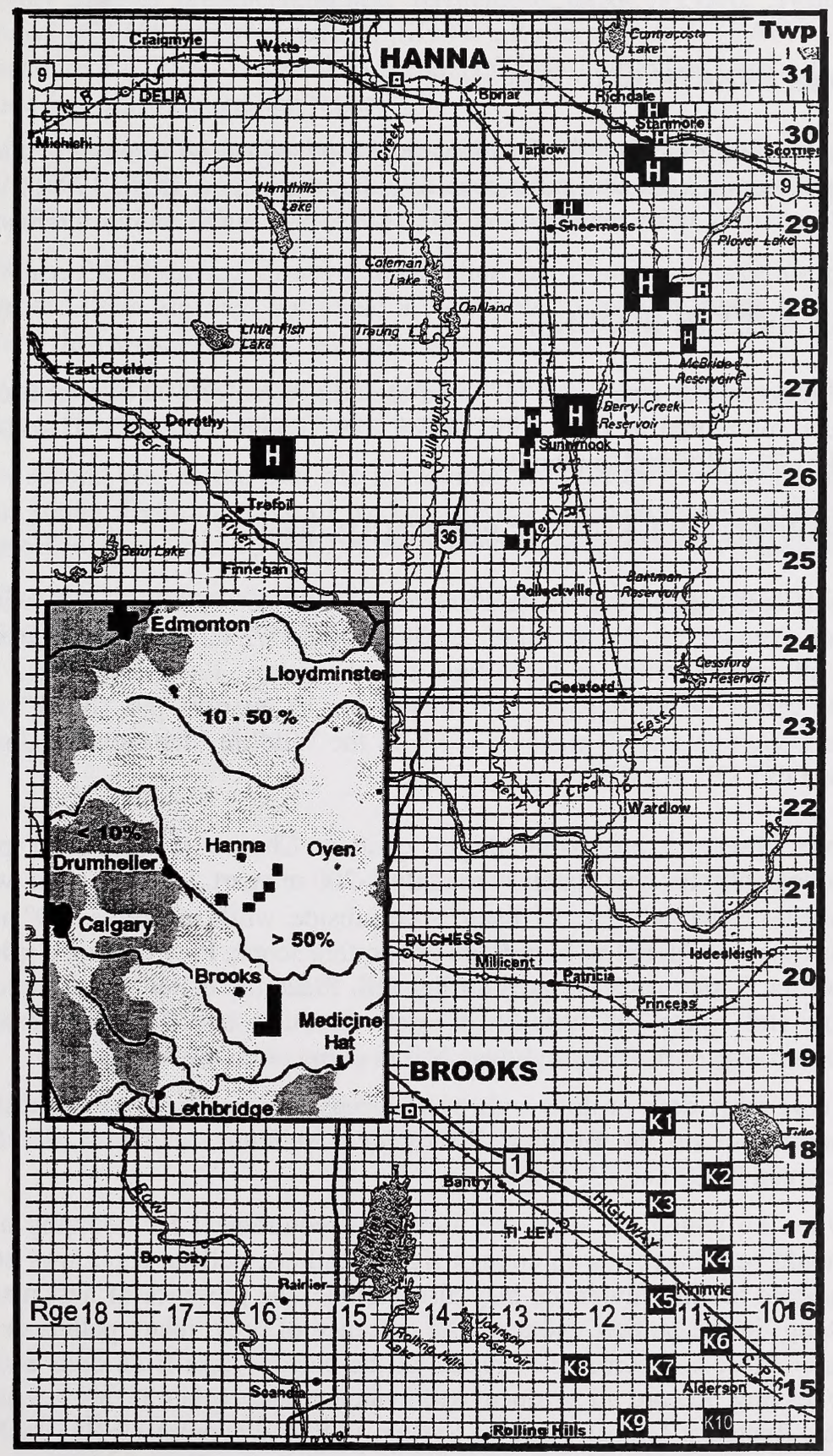

Figure 1. Location of trend blocks in Brooks and Hanna. Inset shows survey areas in respect to remaining percentage of native prairie (adapted from Shyry 1999). 


\section{METHODS (adapted from Shyry 1999)}

Although the same methodology applies to both Brooks and Hanna study areas they will be separated for ease in data presentation.

\section{BROOKS AREA (K-BLOCKS)}

The 10 survey blocks in the Brooks District are comprised of 160 quarter sections. They are named " $K$ " for Kininvie Lake and have been monitored in 1994, 1995, 1997, 1998, 1999 and 2000. Only 128 quarters were surveyed in 1993. All K-blocks fall within the Eastern Irrigation District.

\section{HANNA AREA (H-BLOCKS)}

The 8 survey blocks in the Hanna, or " $\mathrm{H}$ " area are comprised of 109 quarter sections. The Hblocks have been monitored in 1991, 1993, 1994, 1997, 1998, and 2000. The H-blocks are on lands occupied by 21 individual landholders.

\section{BURROWING OWL SURVEY PROTOCOL 2000}

This project will commence June 12 and end when completed, presumably within 2 weeks. Search a quarter section ( $1 / 4$ of a sq. mile, i.e., $1 / 2$ mile by $1 / 2$ mile) at a time, using the middle of roads, road allowances, trails or fence lines as a boundary. Each quarter has an exact GPS location for the center of the quarter. This makes for 16 quarters per "block" and taking all blocks together is enough area to make up $5 \%$ of the Wildlife Management Unit. Record any IN BLOCK and OUT OF BLOCK sightings.

1. Two observers are required per quarter. Choose the elevated points strategically for best visibility roughly 1-200 m apart. Shut off quad, wait 5 minutes to let the effect of disturbance subside, while making a $360^{\circ}$ pan of the quarter with aid of binoculars or spotting scope. Play the taped primary call for $5 \mathrm{~min}$; scan the area during call. Place the caller above the cargo box and rotate the speaker in each direction equally. Now examine nests/roosts or possible sightings before going on to the next quarter.

2. Avoid rainy days or days with wind speeds greater than approximately 20 $\mathrm{km} / \mathrm{hr}$. B-4 on the Beaufort Windscale. Optimum conditions should be between 06:00 and 13:00 hrs.

3. When no young are seen, the minimum requirement for counting a nest should be a burrow with enough signs (feathers, pellets, legs, jaws etc) to indicate nesting. Evidence may also include: the presence of nest material (dung) in the burrow entrance, the presence of prey, many pellets or prey parts, loose soil across the breadth of the burrow floor from owls entering or leaving. Record all pertinent owl evidence and explain if this is a nest or not. Record a Global Position System (GPS) Waypoint (WPT) in North American Datum (NAD) 27 (Canada) using the Universal Transverse Mercator (UTM) format. 
4. To maximize the amount of information obtained, record additional data on plots including landscape, human occupation, and habitat features, and \% visibility. Record in addition to burrowing owl (BUOW), the following other species presence/absence: ferruginous hawk (FEHA), Swainson's hawk (SWHA), short-eared owl (SEOW), Baird's Sparrow (BASP), upland sandpiper (UPSA), loggerhead shrike (LOSH), long-billed curlew (LBCU) and any other uncommon fauna.

5. The data sheet is designed for 4 sections per sheet (16 quarters). Conduct 2 - 800 m Richardson's ground squirrel transects per block recording used and all burrows either side of the quad up to 1 meter away.

6. When the observers discover owls after the 10-min. observation period, record them anyway, but make a clear note to explain where they were, how they were found and why they were missed.

7. Adherence to the established protocol ensures that bias is minimized between observers and different years.

8. A second visit to the nest site is required in mid-July to count the number of young. Return to each of the located nest sites and install an ID marker pin $1 \mathrm{~m}$ away from the head of the burrow (area opposite the mound).

9. Provide accurate and complete data sheets, detailed expense accounting, and Project Summary by end of July. 


\section{RESULTS}

Table 1. Results of K-block burrowing owl 2000 survey.

\begin{tabular}{|c|c|c|c|c|c|c|c|c|c|}
\hline \multirow[t]{3}{*}{ WPT } & \multirow[t]{3}{*}{ DATE } & \multirow[t]{3}{*}{$\mathrm{K} \#$} & \multirow{3}{*}{$\begin{array}{r}\text { TOTAL } \\
\text { \# OWLS }\end{array}$} & \multirow{3}{*}{\begin{tabular}{|l} 
BURROW \\
NUMBER \\
\end{tabular}} & \multicolumn{5}{|c|}{ PRODUCTIVITY SEARCH } \\
\hline & & & & & \multirow[b]{2}{*}{ DATES } & \multirow{2}{*}{$\begin{array}{l}\text { TOTAL } \\
\text { OWLS }\end{array}$} & \multirow{2}{*}{\begin{tabular}{|c|} 
YOUNG \\
SEEN \\
\end{tabular}} & \multicolumn{2}{|c|}{ NEST } \\
\hline & & & & & & & & 2000 & 1999 \\
\hline B00006 & 12-Jun & 1 & 2 & A5776 & 7-Jul & 1 & 0 & $\mathrm{y}$ & $\mathrm{n}$ \\
\hline BO0007 & 12-Jun & 2 & 2 & A5799 & 9-Jul & 11 & 9 & $\mathrm{y}$ & $\mathrm{y}$ \\
\hline BO0008 & 12-Jun & 2 & 2 & A5781 & 18-Jul & 5 & 3 & $\mathrm{y}$ & $\mathrm{y}$ \\
\hline BO0009 & 12-Jun & 2 & 2 & A5800 & 7-Jul & 7 & 6 & $y$ & $\mathrm{n}$ \\
\hline BO0011 & 13-Jun & 3 & 1 & A5797 & 7-Jul & 0 & 0 & $\mathrm{n}$ & $\mathrm{y}$ \\
\hline BO0012 & 13-Jun & 3 & 1 & A5778 & 7-Jul & 6 & 3 & $\mathrm{y}$ & $\mathrm{n}$ \\
\hline BO0013 & 14-Jun & 5 & 1 & A5767 & 18-Jul & 5 & 4 & $y$ & $\mathrm{y}$ \\
\hline COURT98 & 14-Jun & 5 & 1 & A5768 & 7-Jul & 8 & 7 & $\mathrm{y}$ & $\mathrm{y}$ \\
\hline BO0010 & 14-Jun & 6 & 2 & A5773 & 7-Jul & 8 & 6 & $\mathrm{y}$ & $y$ \\
\hline 0016 & 14-Jun & 6 & 1 & off & 7-Jul & & & off & \\
\hline 0010 & 21-Jun & 8 & 1 & off & 7-Jul & & & off & \\
\hline BO0014 & 17-Jun & 9 & 2 & BWC 078 & 7-Jul & 9 & 7 & $y$ & $\mathrm{n}$ \\
\hline \multicolumn{3}{|c|}{ TOTAL BIRDS OBSERVED } & & 18 & & 59 & 45 & & \\
\hline \multicolumn{3}{|c|}{ TOTAL BIRDS IN BLOCK } & & 16 & \multicolumn{2}{|c|}{ AVERAGE } & 5.0 & $y=9$ & $y=6$ \\
\hline \multicolumn{3}{|c|}{ TOTAL BIRDS OFF BLOCK } & & 2 & & & & & \\
\hline \multicolumn{3}{|c|}{ TOTAL LOCATIONS } & & 12 & & & & $y=$ & yes \\
\hline \multicolumn{4}{|c|}{ ONLY LOCATIONS INSIDE K BLOCKS } & 10 & & & & $\mathrm{n}=$ & no \\
\hline \multicolumn{8}{|c|}{ OFF BLOCK TOTAL } & & \\
\hline 0016 & 14-Jun & & 1 & & & & & & \\
\hline \multirow[t]{2}{*}{0010} & 21-Jun & & 1 & & & & & & \\
\hline & & & 2 & & & & & & \\
\hline \multicolumn{2}{|c|}{ MISSED IN SURVEY } & $\mathrm{K}-\mathrm{BLK}$ & TOTAL & & & & & & \\
\hline \multicolumn{3}{|c|}{ (reported by various observers) } & \# OWLS & & & & & & \\
\hline \multirow[t]{2}{*}{ COURT98 } & $6 / 19 / 99$ & 5 & 1 & & & & & & \\
\hline & TOTAL & & 1 & & & & & & \\
\hline Observers: & \multicolumn{2}{|l|}{ K-BLOCK } & & & & & & & \\
\hline R. Russell & \multicolumn{2}{|l|}{$2,4,6,8$} & & & & & & & \\
\hline D. Shyry & $2,4,6,8$ & & & & & & & & \\
\hline D. Scobie & $1,3,5,7, \mathrm{C}$ &, 10 & & & & & & & \\
\hline C. Scobie & $1,3,5,7,9$ & & & & & & & & \\
\hline R. Sissons & \begin{tabular}{|l|l|l}
10 & \\
\end{tabular} & & & & & & & & \\
\hline Observers: & Productivit & y Count & & & & & & & \\
\hline R.Russell & $2,6,9$ & & & & & & & & \\
\hline P. Patterson & \begin{tabular}{|l|l}
$2,6,9$ \\
\end{tabular} & & & & & & & & \\
\hline D.Scobie & $1,3,5,2,6$ & & & & & & & & \\
\hline A.Fraz & $1,3,5$ & & & & & & & & \\
\hline NO YOY W & ERE OBSE & RVED I & URING K- & BLOCK SU & RVEY 20 & & & & \\
\hline 45 & YOY WEF & E OBS & RVED IN & PRODUCTI & VITY SE & ARCHES & & & \\
\hline 6 & 2000 BUR & ROWS & NERE MAI & RKED & & & & & \\
\hline
\end{tabular}


Table 2. Results of H-block burrowing owl 2000 survey.

\begin{tabular}{|c|c|c|c|c|c|c|c|c|}
\hline \multirow[t]{2}{*}{ WPT } & \multirow[t]{2}{*}{ DATE } & \multirow[t]{2}{*}{$\mathrm{H} \#$} & \multirow{2}{*}{$\frac{\text { TOTAL }}{\# \text { OWLS }}$} & \multirow{2}{*}{\begin{tabular}{|l|} 
BURROW \\
NUMBER \\
\end{tabular}} & \multicolumn{4}{|c|}{ PRODUCTIVITY SEARCH } \\
\hline & & & & & & TOTAL & YOUNG & NEST \\
\hline & & & & & DATES & OWLS & SEEN & 2000 \\
\hline $\mathrm{H} 2 \mathrm{BO} 2$ & 17-Jun & 2 & 2 & $2407-32071$ & 6-Jul & 7 & 6 & $\mathrm{y}$ \\
\hline \multirow[t]{3}{*}{$\mathrm{H} 2 \mathrm{BO} 01$} & 17-Jun & 2 & 2 & $2407-32438$ & 6-Jul & 6 & 4 & $\mathrm{y}$ \\
\hline & & & & & & 13 & 10 & $y=2$ \\
\hline & & & & & & AVERAGE & 5.0 & \\
\hline \multicolumn{3}{|c|}{ TOTAL BIRDS OBSERVED } & & 4 & & & & \\
\hline \multicolumn{3}{|c|}{ TOTAL BIRDS IN BLOCK } & & 4 & & & & \\
\hline \multicolumn{3}{|c|}{ TOTAL BIRDS OFF BLOCK } & & 0 & & & & \\
\hline \multicolumn{3}{|c|}{ TOTAL LOCATIONS } & & 2 & & & & \\
\hline \multicolumn{4}{|c|}{ ONLY LOCATIONS INSIDE H BLOCKS } & 2 & & & & \\
\hline \multirow{2}{*}{\multicolumn{2}{|c|}{ MISSED IN SURVEY }} & & & & & & & \\
\hline & & H -BLK & TOTAL & & & & & \\
\hline \multicolumn{3}{|c|}{ (reported by various observers) } & \# OWLS & & & & & \\
\hline AMOCO 1 & 6-Jun & 6 & 6 & & & & & \\
\hline \multirow[t]{2}{*}{ SCOBIE 1} & 6-Jul & 6 & 7 & & & & & \\
\hline & TOTAL & & 13 & & & & & \\
\hline \multicolumn{2}{|c|}{ Observers: H-BLOCK } & & \multicolumn{3}{|c|}{ Observers: Productivity Counts } & & & \\
\hline \multicolumn{2}{|c|}{ Joel Nicholson } & & \multicolumn{2}{|c|}{ Joel Nicholson } & & & & \\
\hline \multicolumn{9}{|c|}{ Julie Hauser } \\
\hline \multicolumn{9}{|c|}{ Corey Scobie } \\
\hline & & & & & & & & \\
\hline \multicolumn{9}{|c|}{ No YOY were observed during H-Block survey 2000} \\
\hline 10 & \multicolumn{4}{|c|}{ YOY were observed in Productivity Search } & & & & \\
\hline 2 & \multicolumn{4}{|c|}{2000 BURROWS WERE MARKED } & & & & \\
\hline
\end{tabular}


Table 3. Land not surveyed in H-blocks in 2000.

\begin{tabular}{cl}
\hline H block & \multicolumn{1}{c}{ Reason } \\
\hline H2 & Landowner denied access, saying he did not want anyone prowling around on his land, suspect he \\
& had owls as 2 nests found on land to immediate South \\
H2 & As above \\
H3 & Cultivated \\
H6 & Landowner denied access, saying he did not want anyone to know if there were owls on his land due \\
& to the "laws out there today", he also feels that the harrassement of the owls by biologists etc has \\
& contributed to their decline and they are "starting to come back once people are leaving them alone" \\
H6 & As above \\
H6 & As above \\
H6 & As above \\
H6 & As above \\
H6 & As above \\
H6 & As above \\
H6 & As above \\
H8 & Cultivated \\
H8 & Cultivated \\
H8 & Cultivated \\
H8 & Cultivated \\
&
\end{tabular}

Table 4. Dates of trend block surveys.

\begin{tabular}{lll}
\hline Year & Hanna & Brooks \\
\hline 1991 & July 5 - July 23 & No Survey \\
1993 & July 8 - July 23 & June 21 - July 20 \\
1994 & July 8 - July 15 & June 21 - June28 \\
1995 & No Survey & June 19 - July 28 \\
1997 & July 14 - July 24 & June 7 - June 27 \\
1998 & July 2 - July 11 & June 17 - June25 \\
1999 & Not Surveyed & June 14 - June 19 \\
\hline 2000 & June12 - June 21 & June 12 - June 21 \\
\hline
\end{tabular}

Table 5. Number of nests observed during surveys.

\begin{tabular}{lcccccccc}
\hline & 1991 & 1993 & 1994 & 1995 & 1997 & 1998 & 1999 & 2000 \\
\hline Brooks & & 6 & $2 *$ & 12 & 14 & 10 & 10 & 9 \\
Hanna & 23 & $14 *$ & 9 & & 2 & 4 & & $2 *$ \\
\hline
\end{tabular}

*Not complete survey (less area surveyed). 
Figure 2. Nests per $100 \mathrm{~km}^{2}$

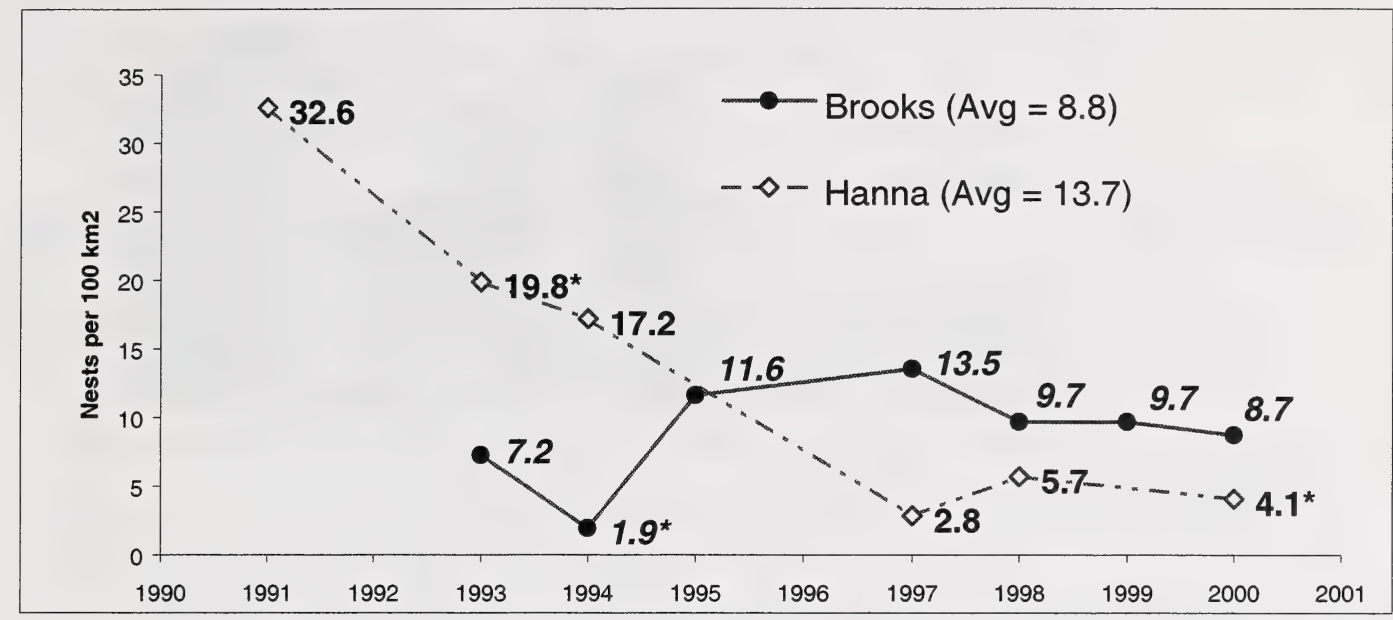

Figure 3. Brooks K-block trend (linear regression).

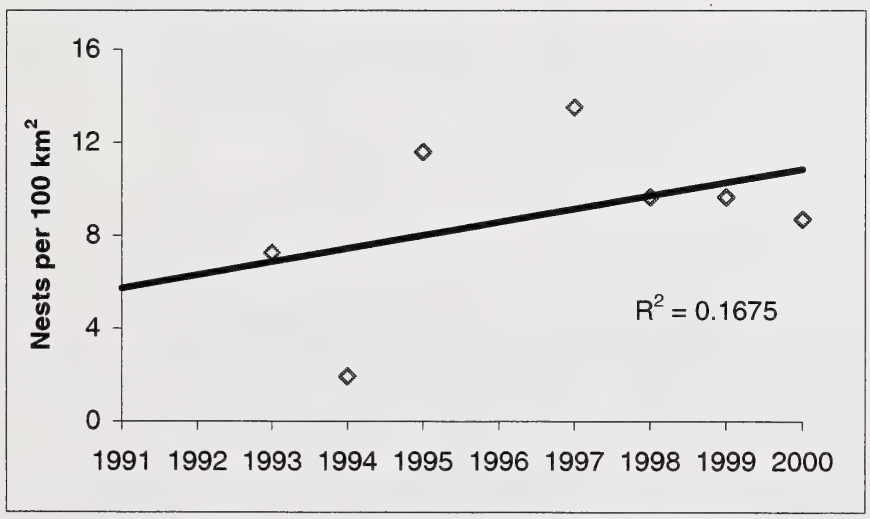

Figure 4. Hanna H-block trend (linear regression).

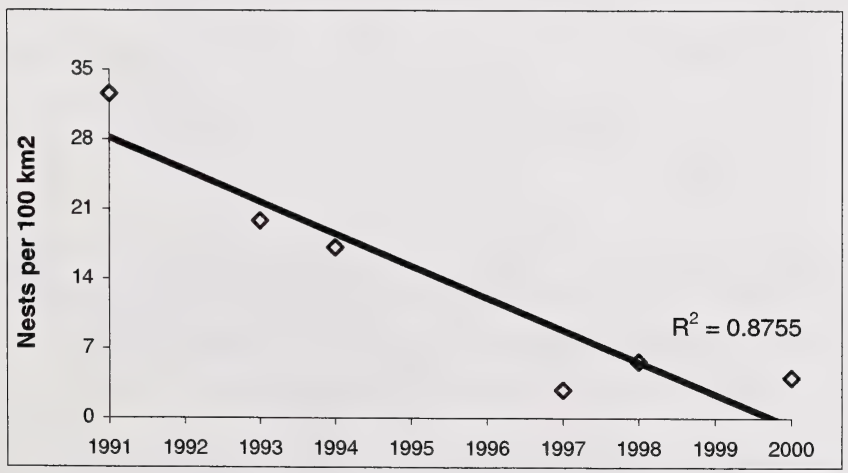


Figure 5. Average number of juvenile owls observed per successful nest site.

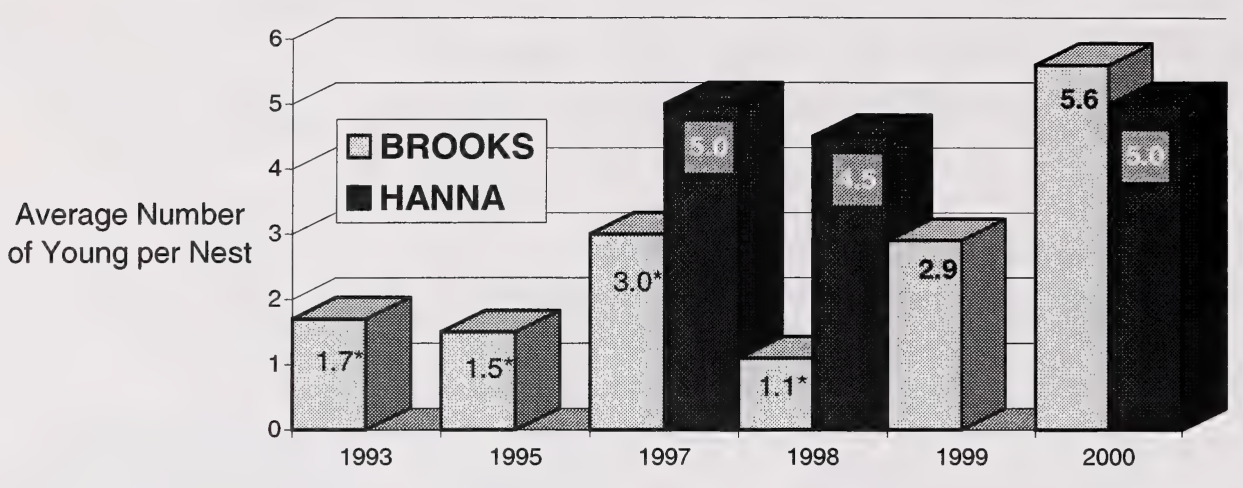

*Incidental Observations

Table 6. Average number of juvenile owls observed per successful nest site.

\begin{tabular}{lcccccc}
\hline & 1993 & 1995 & 1997 & 1998 & 1999 & 2000 \\
\hline BROOKS & 1.7 & 1.5 & 3 & 1.1 & 2.9 & 5.6 \\
HANNA & $\mathrm{N} / \mathrm{S}$ & $\mathrm{N} / \mathrm{S}$ & 5 & 4.5 & $\mathrm{~N} / \mathrm{S}$ & 5 \\
\hline
\end{tabular}

$\mathrm{N} / \mathrm{S}=$ Not Surveyed

\section{DISCUSSION}

There were several problems encountered while doing the H-blocks. Out of the 109 quarter sections, 33 were not searched as detailed in Table 3. Access was denied for 26 of the quarter sections and the remaining 7 were under cultivation. Two nests were found during the survey. Two additional nests were detected later. One was located near pipeline construction in an area where access had been denied. The other nest was found within a previously searched area bringing the total of known nests in the H-blocks to four.

Portions of the southern K-blocks were subject to a violent hailstorm June 12 or 13, 2000. This may have caused adult mortality on some nests and therefore possible lower productivity. The severity of the hail storm was evident by flattened vegetation, injured and dead birds found during surveys and deep "pot-marking" noted on bare earth mounds. Initial investigations of waterfowl mortality found hundreds dead from hail damage. Four days during the survey period were lost due to poor weather (i.e., wind and rain).

One nest in $\mathrm{K} 5$ has proven to be troublesome for a variety of observers as it has not been detected for 3 years. This nest was originally reported after the survey had been completed in 1998. Missing the owls during the survey could be attributed to topography or habituation to the call playback.

In 1999, an effort was made to permanently mark any nest sites that could be located in the Kblocks from 1997-1999. This practice was continued in 2000 with 6 burrows being marked. One 
nest in K2 (\#A5799) was reported by a reliable source as being active in 1999. The nest, shown in Figure 8, was struck by tragedy on July 13 when the female was found dead as a suspected road mortality. Over a 2-week period, the 9 young were supplementary fed with 20 small mammals obtained through trapping and purchases from a local pet store. The number of owlets that survived to fledgling is unknown.

\section{RECOMMENDATIONS}

a The survey should be repeated in 2001 for both the $\mathrm{K}$ and H-blocks.

a Eliminate cultivated blocks from H-block surveys.

a Historic nest sites should be checked before the observers leave the area.

a Collect more biological, geophysical information on the trend blocks.

a Develop Arcview@ Geographical Information System (GIS) themes for K and H-blocks.

- Richardson's ground squirrel and other incidental observations should be evaluated.

- Keep an up to date telephone list of landholders for the H-blocks.

- Send out thank you cards and a simple survey summary to landholders. This would explain the survey and educate landholders on the status of the burrowing owls in their area. This may also help with access in future years. Some of the landholders did not seem to be aware that their property had been in this type of survey for many years. 


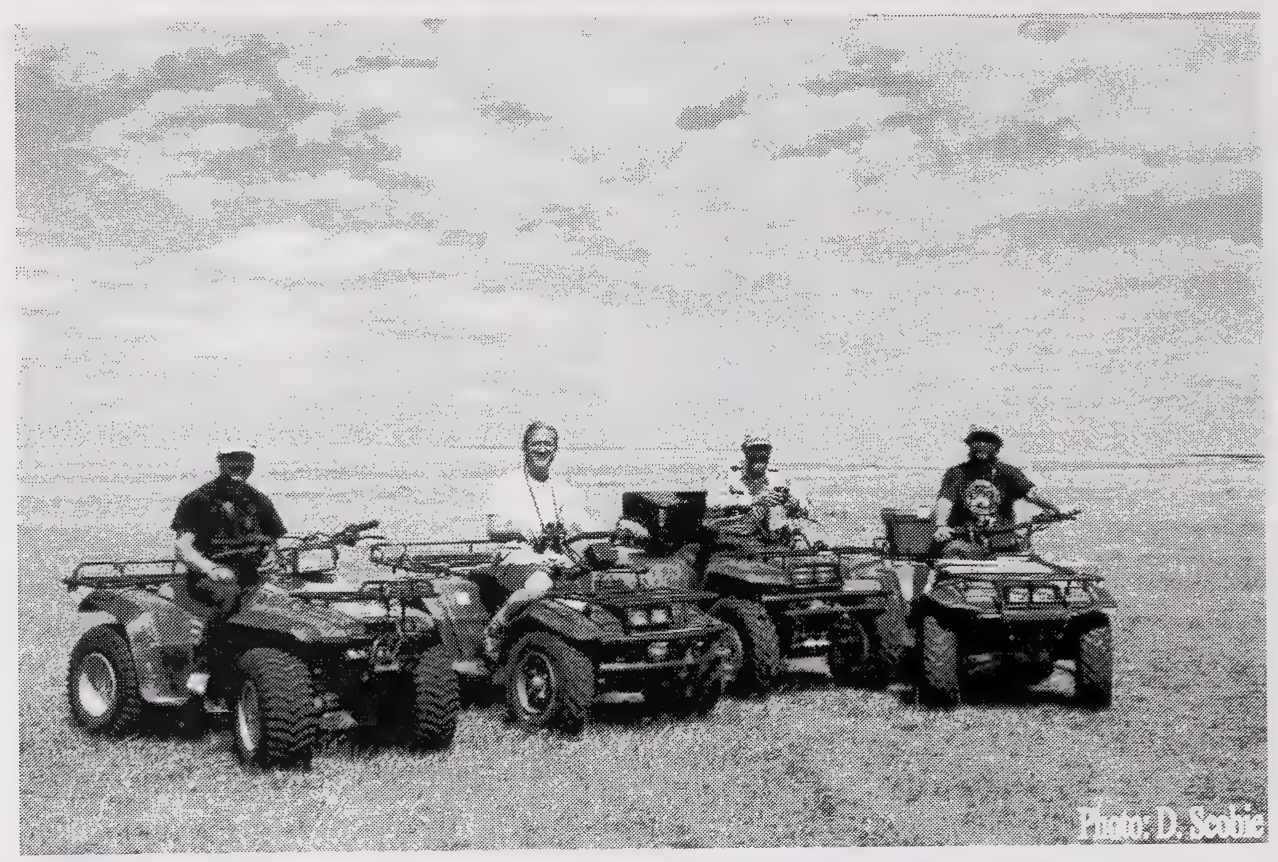

Figure 6. Part of the burrowing owl survey crew 2000 (left to right D. Shyry, R. Sissons, R. Russell and D. Scobie).

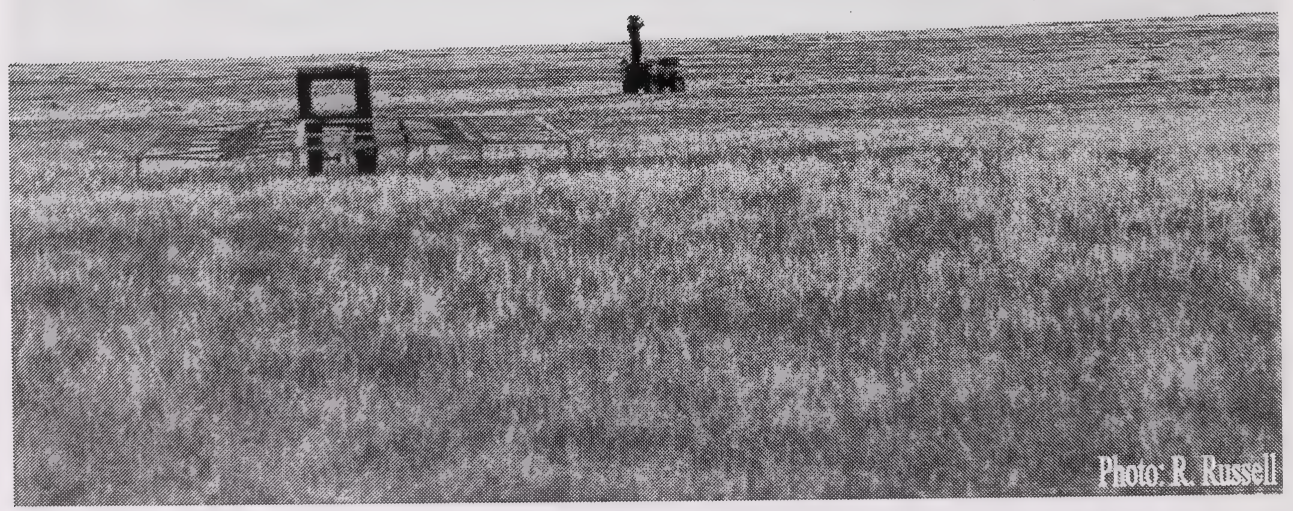

Figure 7. Surveying for burrowing owls in K8. 


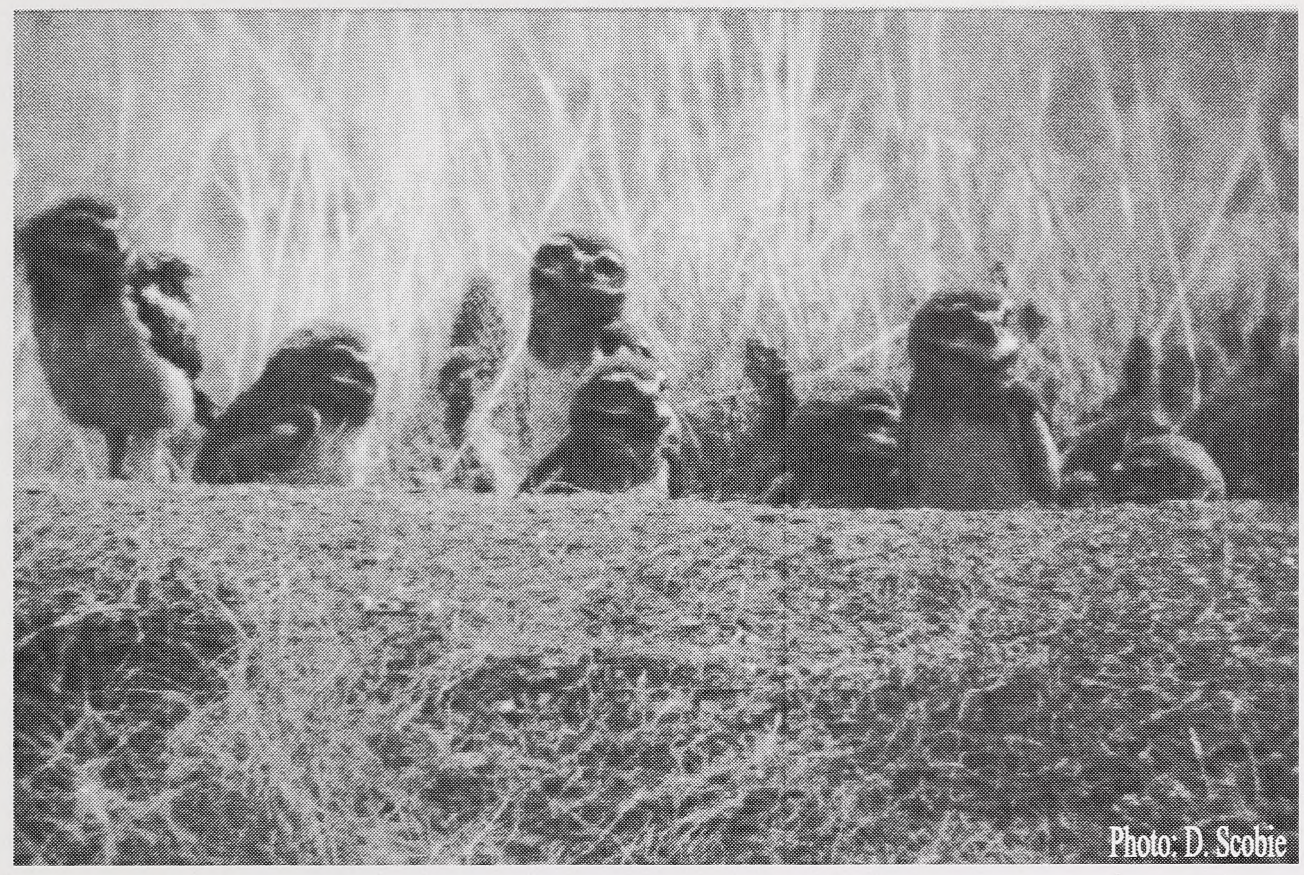

Figure 8. K-2 nest \#A5799.

\section{LITERATURE CITED}

Shyry, D. T. 1999. A summary report on Burrowing Owl (Athene cunicularia) population trend surveys in southern Alberta: 1991-1998. Alberta Environment, Wildlife Management Division, Occasional Paper, Alberta Natural Resources Service, Edmonton, AB. 16 pp. 

National Library of Canada

Bibliothèque nationale du Canada

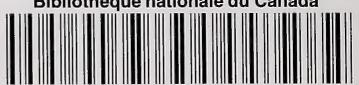

33286523344642 